\title{
Involvement of Lipid Rafts and Caveolins in UVA Signaling
}

\author{
Susanne Grether-Beck ${ }^{*}$ and Jean Krutmann
}

IUF, Heinrich-Heine University Duesseldorf, Duesseldorf, Germany

\begin{abstract}
This review provides an overview over the burden solar radiation confers to human skin. Individual exposure doses vary not only due to different ambient UV doses depending on season, time of day, geographical position and weather conditions, but just as importantly to seasonal variation in behaviour. The general photobiological mechanisms underlying UVA, UVB and infrared A signaling are marked. Rafts are tightly packed, ordered and dynamic membrane microdomains rich in sphingolipids and cholesterol. They contribute to signaling events by trapping signaling molecules e.g. receptors or enzymes in order to render them active or inactive. A special subtype of rafts are caveolae also found in basal keratinocytes representing a flask-shaped invagination of the cytoplasmic membrane which are stabilized by caveolins serving as a scaffolding protein to organize lipids and signal transducing proteins. Within UVA signaling these membrane domains have been identified to be a target and a source for formation of reactive oxygen species in keratinocytes. UVA responsiveness with regards to gene expression depends on the ratio of cholesterol $v s$ ceramide in rafts and on the presence of caveolin-1. Cholesterol, phytosterols or several triterpenoids can stabilize these raft structure leading to inhibition of UVA signaling, whereas increased levels of 7-dehydrocholesterol found in Smith-Lemli-Opitz patients suffering from enhanced photosensitivity mainly towards UVA destabilize rafts.
\end{abstract}

Keywords: UVA, signaling, rafts, caveolin.

\section{ULTRAVIOLET RADIATION}

The solar radiation reaching the surface of earth is containing (i) UV radiation that makes up about $6.8 \%$ of the electromagnetic radiation human skin is exposed to, (ii) visible light contributing about $38.9 \%$ and (iii) infrared radiation accounting for about $54.3 \%$ of total radiation [1, 2]. Oxygen formed by photosynthetic activity on earth constitutes a very effective filter in the outer reaches of our atmosphere that absorbs the most energetic and therefore most harmful short-wave solar UVC (200-280 nm) radiation. In this process, oxygen molecules split up and recombine to form ozone. This ozone layer in the stratosphere in turn can also absorb UV radiation of higher wavelengths up to about $310 \mathrm{~nm}$. Therefore, a part of the mid wavelength, mid energy UVB is absorbed and the remaining part can reach ground level to interact with human skin. In contrast, the long-wave length, low energy UVA (315-400 nm) completely passes the protective atmosphere $[3,4]$. The exposure dose of UVB radiation on earth constitutes about $1-10 \%$ of total UV exposure [5]. The remaining 90 to $95 \%$ are the long-wave UVA $[6,7]$. For sunlight, in locations such as Australia the spectral irradiance in the UVA range is approximately one hundred times higher than in the UVB range. The total ambient UV dose on ground level is highly variable and depends on season, time of day, geographical position and weather conditions. On a summer day at noon in a geographic position between latitude $30^{\circ}$ to $35^{\circ}$ North (e.g. in Memphis, TN, USA or New Orleans, LA, USA), a UVA dose of $300 \mathrm{KJ} / \mathrm{m}^{2}$ can easily be obtained during 1 to 2 hours of exposure [8]. 10 degrees further to the North, e.g. in

\footnotetext{
*Address correspondence to this author at the IUF, Cell Biology, Auf'm Hennekamp 50, 40225 Duesseldorf, Germany; Tel: 00492113389303; Fax: 00492113389330; E-mail: Grether-Beck@uni-duesseldorf.de
}

Austin, MN, localized $43^{\circ}$ North, a similar UVA dose is obtained in August during 5 hours and 42 minutes of sunshine [9]. Even in northern European countries, e.g. England, the estimated population exposure to UVA based on the measurement of ambient radiation is $15.000 \mathrm{KJ} / \mathrm{m}^{2}$ [10]. In this context, it is important to realize that there are large variations in daily personal exposure, more so for indoor workers living in northern Europe than for those resident, e.g. in Florida, which are due not only to seasonal changes in ambient exposure, but just as importantly to seasonal variation in behaviour [11]. Not surprisingly, holiday and summer weekend exposure account for the largest daily UV doses as observed from personal UV monitoring studies in Denmark [12-14]. About one-third of the annual facial exposure for northern Europeans is received during a 2-week summer vacation taken at home latitudes $[11,12]$. The individual UV exposure will be further increased by the trend for overseas holidays to more sunny destinations.

Over the last two decades evidence has been growing that UVA and UVB differ with regards to their effects on human skin. The mid wave UVB penetrates down only to the basal membrane, the deepest layer of the epidermis. UVB was shown to be the main cause for sunburns [15-18], and, finally, the development of skin cancers such as basal cell carcinoma and squamous cell carcinoma [19-21]. As chromophores for UVB DNA, leading to cyclobutane pyrimidine dimer formation [22], but also tryptophan resulting in a photoproduct binding to the arylhydrocarbon receptor [23], have been identified.

In contrast, the long-wave UVA can deeply penetrate to the dermal compartments of the skin. Here, the UVA can induce oxidative stress [24] leading to oxidative DNA damage such as 8-oxo-guanine formation [20, 25], 
mitochondrial DNA deletions [26, 27] and premature aging also called photoaging of the skin [28]. Moreover, phototoxic and photoallergic reactions after UVA irradiation have been observed due to interactions with drugs, plant ingredients, sun screens or skin care products $[29,30]$. The adverse effects of UVB and UVA, respectively, with regards to melanoma are still under debate [31,32]. UVA is known to induce mutations in cultured cell lines and melanomas in animal models such as the hybrid fish Xiphophorus and the opossum (Monodelphis domestecia) [33]. Additionally, immunosuppression has been observed in animal models and in humans $[34,35]$. Some epidemiological studies suggest a cause effect relationship between UVA exposure and the induction of melanoma [36-38]. The observed dramatic increase in cutaneous cancers in sun-exposed areas of the skin of immunosuppressed patients who underwent organ transplantation is attributed to decreased innate cancer surveillance due to panimmunosuppression by drug therapy and exposure to UVA and UVB [39-41].

It is known that UV radiation is a potent inducer of oxidative stress leading to changes in gene expression in cells of human skin. The underlying photochemical and photobiological mechanisms are of general interest as UVA induced gene expression is thought to be relevant for photoaging [28], photocarcinogenesis [42], and the pathogenesis of the most frequent photodermatosis polymorphic light eruption [43, 44]. For the sake of completeness, it has to be mentioned that infrared A radiation deeply penetrates human skin and even reaches subcutaneous tissues. Infrared A radiation leads to an increase in reactive oxygen species within the mitochondria resulting in MAPkinase activation and finally increase in matrix metalloproteinase 1 expression [45].

Irradiation of cultured cells or human skin with physiological doses of UVA results in the formation of reactive oxygen species (ROS) [24] specially singlet molecular oxygen [46, 47]. ROS are also generated in unirradiated cells within mitochondria in the respiratory chain due to imperfect one electron reduction of oxygen to superoxide [48]. Moreover, the formation of ROS has been attributed to enzymatic reactions e.g. plasma membrane localized NADPH oxidases [49] after UVA and UVB exposure [50,51]. Also, a direct formation of singlet oxygen and other reactive oxygen species by photochemical reactions from UVA irradiated lipids and other endogenous chromophores e.g. flavins or NADH / NADPH was observed [47].

\section{RAFTS AND UVA SIGNALING}

Lipid rafts or more precisely membrane rafts are small $(10-200 \mathrm{~nm})$, heterogeneous, highly dynamic, sterol- and sphingolipid-enriched domains in the lipid bilayer membranes that compartmentalize cellular processes. Small rafts can sometimes be stabilized to form larger platforms through protein-protein and protein-lipid interactions [52]. As the size of rafts is below the resolution of light microscopy, first evidence for these small structures came from a particularly large subtype of rafts the so-called caveolae, which have been described as flask shaped invaginations of the plasma membrane $[53,54]$. In many cell types the submicroscopic lipid rafts sometimes assemble into higher-order structures of size in the micrometer range [55] the so-called "flotillas" of rafts [56]. These structures are within the resolution of the light microscope and can easily be visualized by labeling their ganglioside component with fluorescent labels or antibodies against the main gangliosides GM1 or GM3. In primary human keratinocytes as well as in $\mathrm{HaCaT}$ cells large lipid raft aggregates could be stained with a fluorescein-tagged cholera toxin (FITC-CTX), that binds exclusively to the raft marker GM1 [57]. Differences were observed in membrane raft distribution with regards to attachment and confluency. Unattached cells showed a homogenous staining with no detectable rafts, while attached subconfluent cells showed a redistribution of GM1 towards the margins of the cells with a similar staining pattern for all cells. In confluent HaCaTs, GM1 redistributed to membrane areas of adjacent $\mathrm{HaCaT}$ cells forming junction-like structures. Moreover, in these cells, two populations could be distinguished differing with regards to the staining intensity of fluorescein-tagged cholera toxin. Using the fluorescent dye carboxy-2', 7'-dichlorodihydrofluorescein for staining of intracellular levels of reactive oxygen species a correlation between FITC-CTX staining of rafts and the cellular level of ROS content was observed. After UVA irradiation a significant difference in ROS generation was observed that correlates with FITC-CTX staining. The UVA response in highly FITC-CTX stained cells generated higher amounts of reactive oxygen species than in low FITC-CTX stained cells. The results obtained with this elegant experiment using double staining with fluorescence probes indicative for synthesis of reactive oxygen species and the raft marker GM1 indicate a direct involvement of rafts in the formation of ROS. Disruption of raft integrity using $\beta$ methylcyclodextrin to extract the cholesterol from the cytoplasmic membranes did not change the staining pattern of fluorescein-tagged cholera toxin, but dramatically reduced the formation of ROS no matter whether the cells were irradiated or not. This inhibitory effect of cholesterol depletion on formation of ROS could be reversed after cholesterol repletion [58]. These results imply that rafts are important components in the regulation of oxidative stress and that their disruption diminishes the formation of ROS.

The correlation of UVA irradiation, formation of ROS and the generation of prostaglandin E2 with increased photosensitivity has been addressed by Irene Kochevar's laboratory $[59,60]$. Increased photosensitivity particularly towards UVA has been observed in patients suffering from Smith-Lemli-Opitz syndrome. These patients frequently exhibit an increased susceptibility towards solar UV radiation [61-63]. It is known that this autosomal, recessive genetic disorder is caused by deletions as well as missense and nonsense mutations in the gene coding for 7dehydrocholesterol reductase. The resulting lowered expression of the corresponding protein $\Delta 7$-sterol-reductase results in decreased cholesterol synthesis [64]. Therefore, Smith-Lemli-Opitz patients show decreased cholesterol serum levels [61-63]. A cell culture model for Smith-LemliOpitz was established by partially replacing cholesterol by 7 dehydrocholesterol in keratinocytes using a triple treatment of (i) inhibition of cholesterol de novo synthesis by AY9944, (ii) depletion of cholesterol by $\beta$-methylcyclodextrin and (iii) addition of 7-dehydrocholesterol. In this cell model the UVA-induced $\left(10 \mathrm{KJ} / \mathrm{m}^{2}\right)$ formation of reactive oxygen 
species and of prostaglandin E2 was significantly increased $[59,65]$. This increased formation of ROS was considerably inhibited by preincubation with the NADPH oxidase inhibitor diphenyleneiodonium. Additional indications for the function of NADPH oxidase in the formation of ROS came from activity assays, where a several-fold increase was observed in Smith-Lemli-Opitz model keratinocytes as compared to normal control keratinocytes. Likewise, the specific knockdown of the NADPH oxidase subunit Nox1 significantly decreased UVA-induced formation of ROS and of prostaglandin E2. The UVA-induced formation of prostaglandin E2 [66] is thought to constitute one of the main reasons for the observed increased photosensitivity of Smith-Lemli-Opitz patients. As the calcium dependent phospholipase A2 is the prime enzyme for releasing arachidonic acid from the lipid membranes in keratinocytes, calcium release, the activity of phospholipase A2 and the release of prostaglandin E2 was assessed with regards to the effect of general antioxidants, inhibition of NADPH oxidase, inhibition of phospholipase A2 and calcium chelators. The results point to activation of NADPH oxidase as the key source of UV-induced formation of ROS in Smith-LemliOpitz model keratinocytes. Furthermore, the rapid increase in prostaglandin E2 is caused by an increasing calcium concentration in the cell and the ensuing activation of phospholipase A2.

Co-localization experiments for GM1 and the raft marker proteins caveolin-1 and flotillin-2, respectively, indicate that in Smith-Lemli-Opitz keratinocytes the rafts are destabilized leading to a release of the raft proteins and a homogenous distribution in the intracellular space. Cholesterol depletion of normal keratinocytes gave a similar picture for the localization of the raft proteins. Interestingly, by a free radical mechanism liposomes containing 7dehydrocholesterol were more rapidly oxidized than cholesterol containing liposomes. This was interpreted that in addition to effects on the activity of enzyme(s) direct effects within the lipids occur that lead to increased formation of reactive oxygen species.

All told, these data were interpreted as 7dehydrocholesterol disrupts membrane rafts leading to an increased formation of reactive oxygen species in SmithLemli-Opitz model keratinocytes due to an increased activity of NADPH oxidase. Also a rise of intracellular calcium levels activates calcium dependent phospholipase A2 activity resulting in an increased formation of prostaglandin E2. Interestingly, the increased formation of reactive oxygen species was not observed by disruption of rafts with $\beta$ methylcyclodextrin in control keratinocytes, pointing to an additional effect of 7-dehydrocholesterol involved in the increased sensitivity towards free radical oxidation. Besides, this report states that 7-dehydrocholesterol disrupts membrane rafts in cells, which is in contrast to studies performed on model membranes where 7-dehydrocholesterol stabilized rafts even better than cholesterol [67]. A possible explanation for this obvious disagreement might be the more complex structure of both cellular rafts due to the presence of sphingomyelin and proteins and cellular membranes. Studies by Gniadecki and his team using HaCat cells [58] showed increased formation of reactive oxygen species after irradiation with $30 \mathrm{KJ} / \mathrm{m}^{2}$ UVA while immortalized human Smith-Lemli-Opitz model keratinocytes exhibited this effect already after irradiation with $10 \mathrm{KJ} / \mathrm{m}^{2}$ [59]. UVA-induced activation of NADPH oxidase was observed in untreated immortalized keratinocytes at the higher UVA dose of $50 \mathrm{KJ} / \mathrm{m}^{2}$. Interestingly, this UVA-induced activation could be mimicked by cell permeable ceramides [60].

A recent study dealing with UVA-induced upregulation of gene expression in primary human keratinocytes irradiated with the physiological UVA dose of $300 \mathrm{KJ} / \mathrm{m}^{2}$ [8] established that signaling by ceramide and raft signaling were linked with each other [68]. The expression of intercellular adhesion molecule-1 (ICAM-1), that is constitutively absent in keratinocytes, can be induced in this cell type by a variety of stimuli including ultraviolet radiation [69, 70]. ICAM-1 is a specific ligand for lymphocyte function-associated antigen-1 (LFA-1), a cellsurface protein expressed on all leukocytes. The regulated expression of ICAM-1 enables leukocytes to bind to endothelial cells at sites of inflammation and, after migrating into the tissue, to interact with specific target cells, such as keratinocytes. In previous studies the Krutmann group had shown that UVA-induced gene expression is initiated at the level of the cell membrane via generation of singlet molecular oxygen. This leads to the subsequent formation of ceramides from sphingomyelin $[71,72]$ and the activation of transcription factor AP2 and finally upregulation of UVAinducible genes such as ICAM-1. A detailed analysis of the lipid composition of the isolated membrane rafts indicated that irradiation with $300 \mathrm{KJ} / \mathrm{m}^{2}$ decreased the lipid content by $40 \%$ in sphingomyelin and by $60 \%$ in cholesterol. An increase of the UVA-induced mRNA expression of ICAM-1 was observed once the keratinocytes had been depleted by cholesterol using ß-methylcyclodextrin. In contrast, preloading of keratinocytes with cholesterol, but also phytosterols could inhibit UVA-induced ceramide formation, together with activation of AP2 and ICAM-1 upregulation. As cholesterol is known to serve as singlet oxygen or free radical quencher, the generation of so-called signature oxysterols upon UVA irradiation was carefully addressed in keratinocytes which had been preloaded with cholesterol prior to UVA exposure. Using high performance thin layer chromatography, oxysterols were easily detected in in vitro irradiated pure cholesterol. On the other hand, neither singlet oxygen generated nor free radical generated oxysterols could be identified in the samples from keratinocytes, indicating that quenching properties of cholesterol do not play a major role under these conditions. On the level of raft lipid composition, a preloading of cholesterol resulted in a concomitant increase of both cholesterol and sphingomyelin over $200 \%$ as compared to untreated cells, while the ceramide content remained constant. To understand, whether the inhibition of the UVA response was due to the concomitant increase of both cholesterol and sphingomyelin or due to the relative change in either cholesterol or ceramide or sphingomyelin, the UVA responsiveness was addressed after interference with the biosynthesis of cholesterol or sphingomyelin. Hence, the effect of cholesterol, phytosterols, inhibition of 7-dehydrocholesterol reductase by AY9944, and B-methylcyclodextrin in the presence and absence of UVA was assessed. No pattern could be identified where responsiveness towards UVA correlated to the relative increase or decrease of sphingomyelin towards cholesterol either in mass of lipid per mass of protein or in 
molar ratios. Inspired by a paper indicating that ceramides might selectively displace cholesterol from lipid rafts prepared from synthetic lipids [73] the authors also calculated the molar ratios of cholesterol $v s$ ceramide. Comparing the UVA responsiveness detected as ceramide formation and ICAM-1 upregulation to the molar ratios of sphingomyelin and ceramide, an interesting pattern occurred. UVA signaling was observed when the ratio of cholesterol $v s$ ceramide was smaller than 1 , in contrast signaling was abolished upon sterol preloading. Accordingly, addition of synthetic ceramides mimicked the decrease of cholesterol observed after UVA irradiation and preloading of keratinocytes with cholesterol could partially inhibit ceramide induced gene expression.

These results indicate that the ratio of cholesterol vs ceramide in rafts determines signaling. This lead to the more practical conclusion that plant sterols like cholesterol might act as active to protect human skin from UVA-induced adverse effects. Additional studies indicate that application of phytosterol containing creams prevent the UVA-induced upregulation of matrix-metalloproteinase-1 in vitro (unpublished observation).

To find a more precise structure-function relationship between type of sterol and capacity to block UVA responses, several triterpenoids derived from natural materials were analyzed for inhibition of UVA-induced ceramide formation within rafts and gene expression. The results verified and extended the previous conception that sterols but also triterpenoids are highly effective in blocking UVA responses. This UVA protective effect depends on the chemical structure of the molecule as oleanolic acid, but not its isomer ursolic acid abrogates UVAR-induced ceramide release and gene induction although both molecules integrate into rafts with similar efficiency.

\section{CAVEOLIN AND UVA SIGNALING}

Caveolins are integral membrane protein found in the caveolae, which represent a morphologically identifiable subset of rafts leading to an increased surface area of the cells. Several lines of evidence indicate that the caveolin family proteins function as scaffolding proteins to concentrate and organize specific lipids such as cholesterol and sphingolipids and lipid-modified signaling molecules within caveolae membranes. That so many signaling molecule and signaling cascades are regulated by interaction with the caveolins provides a paradigm by which numerous diseases, such as diabetes, cancer, cardiovascular diseases, atherosclerosis, pulmonary fibrosis and muscle dystrophies may be affected by ablation or mutation of these proteins $[74,75]$. To date, 3 different caveolins have been identified: While caveolin 1 and 2 have a relatively ubiquitous distribution pattern, being co-expressed in most differentiated cell types except skeletal muscle fibers and cardiac myocytes, caveolin 3 expression is limited to skeletal muscle, the diaphragm and the heart, although it has been found at stratum granulosum / stratum corneum interface in human skin [76]. The interrelationship between caveolin-1 and cholesterol was discovered when treatment of cells with cholesterol binding agents resulted in flattening of the caveolae. Cholesterol regulates caveolin-1 expression on the transcriptional level by two steroid regulatory binding elements and by stabilisation of the protein $[77,78]$. On the other hand, caveolin-1 also modulates cellular influx and efflux of cholesterol. Caveolin-1 transports cholesterol from the ER to membrane caveolae, where cholesterol is delivered to plasma high density lipoproteins. Extracellular cholesterol enters the cell via clathrin-mediated endocytosis of low density lipoproteins or by a secondary pathway involving caveolae and the scavenger receptor B1 from high density lipoproteins [79].

Most importantly, caveolae and caveolin-1 play an important role in the modulation of cell signal transduction $[80,81]$. Biochemical analysis of isolated caveolae indicated that these structures contain a plethora of signaling molecules such as src-like kinases, heterotrimeric G proteins, or endothelial nitric oxide synthase to name only a few. Caveolin-1 is a protein of 178 amino acids which can be divided into three regions: a cytoplasmic N-terminal domain (residues 1-101); a putative membrane spanning domain (residues 102-134); and a cytoplasmic C-terminal domain residues (135-178) resulting in a hairpin loop allowing both termini to remain entirely cytoplasmic. The homooligomerization domain spans residues 61-101. The distal half of the homo-oligomerization domain (residues 82-101) has been termed the caveolin scaffolding domain [82]. By interaction of this scaffolding domain with an aromatic amino acid based caveolin binding domain usually found in the active catalytic domain of a given caveolae associated protein caveolin can render a molecule inactive within the caveolae e.g. by inhibition of EGF-R autophosphorylation [83] or can activate a pathway as shown for insulin signaling [84]. Environmental stressors such as high osmolarity but not heat shock resulted in a transient phosphorylation of caveolin-1 at tyrosine 14 mediated via p38 MAP kinase and c-Src. Upon phosphorylation, a partial redistribution of caveolin-1 occurs leading to co-localization of tyrosine 14phosphorylated caveolin-1 and focal adhesions te major sites of tyrosine kinase signaling. Similarly, oxidative stress such as $\mathrm{H}_{2} \mathrm{O}_{2}$ but also UVC $\left(360 \mathrm{~J} / \mathrm{m}^{2}\right)$ induced tyrosine $14-$ phosphorylation of caveolin-1 [85].

Similarly, UVA exposure of primary human keratinocytes $\left(300 \mathrm{KJ} / \mathrm{m}^{2}\right)$ resulted in transient phosphorylation of caveolin-1 at tyrosine Y14. This activation was mediated by src family kinases Yes and Fyn activated by phosphorylated Y418. Upon UVA treatment a redistribution of caveolin-1 was observed. Within rafts the amounts of caveolin-1 decreased while the phosphorylated form could be detected in the non raft fraction of the cytoplasmic membrane [86]. UVA-induced caveolin-1 activation can also be mimicked by a singlet oxygen generating system. Functional relevance of caveolin-1 for UVA signaling was demonstrated by retrovirus-mediated RNA interference resulting in prevention of UVA-induced gene expression in keratinocytes. Inhibition of caveolin phosphorylation by src kinase inhibitor Su6656 prevented both UVA-induced caveolin-1 phosphorylation and its translocation from the raft into the membrane. Most importantly, caveolin-1 phosphorylation and translocation were of functional relevance for UVA-induced gene expression, as their inhibition resulted in complete prevention of UVA-induced ICAM-1 expression. Previous studies showed that UVA-induced signaling in keratinocytes was initiated by the formation of second messenger ceramide 
from cell membrane sphingomyelin [72]. Preincubation with Su6656 did not prevent UVA-induced ceramide formation and stimulation of unirradiated keratinocytes with cellpermeable ceramide induced src kinase phosphorylation, indicating that ceramide formation occurred upstream of src kinase activation. These results were verified in caveolin-1 knockout animals (unpublished observation) where ICAM-1 expression did not increase in response to UVA irradiation. These studies clearly demonstrate the pivotal role of raftsignaling in UVA-induced gene expression in human keratinocytes in vitro [86] and in vivo.

\section{CONCLUSIONS}

Microdomains in keratinocytes have been identified to be not only the target for UVA-induced singlet oxygen but also a source of UVA-induced formation of reactive oxygen species. Increased photosensitivity towards UVA as observed in Smith-Lemli-Opitz patients could be attributed to instability of rafts due to 7-dehydrocholesterol instead of cholesterol leading to a higher sensitivity towards oxidative processes and an increased activity of membrane associated NADPH oxidase which in turn results in increased amounts of prostaglandin PGE2 as a consequence of calcium release and activation of phospholipase A2.

UVA responsiveness with regards to gene expression depends on the ratio of cholesterol $v s$ ceramide in rafts and on the presence of caveolin-1. Signaling occurs if the ratio of cholesterol $v s$ ceramide is smaller than 1 , whereas a ratio greater than 1 abolished UVA-induced gene expression in keratinocytes. Besides the changes in the lipid composition also the presence of caveolin-1 is essential to render signaling proteins either in an inactive state within the rafts or activating them.

\section{ACKNOWLEDGEMENT}

We thank Thomas Jaenicke for helpful discussion and critical review of the manuscript.

\section{ABBREVIATIONS}

$\mathrm{UV}=$ Ultraviolet

ICAM-1 = Intercellular adhesion molecule 1

\section{REFERENCES}

[1] Kochevar IE, Pathak MA, Parrish JA. In: Freedberg IM, Eisen AZ, Wolff K, et al., Eds. Fitzpatrick's dermatology in general medicine. New York, McGraw-Hill 1999; pp. 220-9.

[2] Schieke SM, Schroeder P, Krutmann J. Cutaneous effects of infrared radiation: from clinical observations to molecular response mechanisms. Photodermatol Photoimmunol Photomed 2003; 19: 228-34.

[3] De Fabo EC. Arctic stratospheric ozone depletion and increased UVB radiation: potential impacts to human health. Int $\mathrm{J}$ Circumpolar Health 2005; 64: 509-22.

[4] de Gruijl FR, van der Leun JC. Environment and health: 3. Ozone depletion and ultraviolt radiation. CMAJ 2000; 163: 851-5.

[5] Matsui MS, Deleo VA. In: Mukhtar H, Ed. Skin cancer: mechanisms and human relevance. Ann Arbor, CRC Press 1995; pp. 21-30.

[6] Parisi AV, Wong JC. An estimation of biological hazards due to solar radiation. J Photochem Photobiol B 2000; 54: 126-30.

[7] Jean S, Bideau C, Bellon L, et al. The expression of genes induced in melanocytes by exposure to 365 -nm UVA: study by cDNA arrays and real-time quantitative RT-PCR. Biochim Biophys Acta 2001; 1522: 89-96.
[8] Frederick JE, Alberts AD. The natural UV-A radiation environment. In: Urbach F, Ed. Biological responses to ultraviolet A radiation. Overland Parks, KS: Valdenmar Publishing Company 1992; pp. 7-18.

[9] Bode AM, Dong Z. Mitogen-activated protein kinase activation in UV-induced signal transduction. Sci STKE 2003; 167: RE2.

[10] Diffey BL. Population exposure to solar UVA radiation. Eur J Dermatol 1996; 6: 221-2.

[11] Diffey BL. A behavioural model for estimating population exposure to solar ultraviolet radiation. Photochem Photobiol 2008; 84: 371-5.

[12] Thieden E, Philipsen PA, Sandby-Moller J, Heydenreich J, Wulf HC. Proportion of lifetime UV dose received by children, teenagers and adults based on time-stamped personal dosimetry. J Invest Dermatol 2004; 123: 1147-50.

[13] Thieden E, Philipsen PA, Heydenreich J, Wulf HC. UV radiation exposure related to age, sex, occupation, and sun behavior based on time-stamped personal dosimeter readings. Arch Dermatol 2004; 140: 197-203.

[14] Thieden E, Agren MS, Wulf HC. Solar UVR exposures of indoor workers in a Working and a Holiday Period assessed by personal dosimeters and sun exposure diaries. Photodermatol Photoimmunol Photomed 2001; 17: 249-55.

[15] Coles CA, Forbes PD, Davies RE. An action spectrum for photocarcinogenesis. Photochem Photobiol 1996; 43: 275-84.

[16] El-Ghorr AA, Norval M, Lappin MB, Crosby JC. The effect of chronic low-dose UVB radiation on Langerhans cells, sunburn cells, urocanic acid isomers, contact hypersensitivity and serum immunoglobulins in mice. Photochem Photobiol 1995; 62: 326-32.

[17] Kaidbey KH, Grove KH, Kligman AM. The influence of longwave ultraviolet radiation on sunburn cell production by UVB. J Invest Dermatol 1979; 73: 743-5.

[18] Kawachi Y, Xu X, Taguchi S, et al. Attenuation of UVB-induced sunburn reaction and oxidative DNA damage with no alterations in UVB-induced skin carcinogenesis in Nrf2 gene-deficient mice. J Invest Dermatol 2008; 128: 1773-9.

[19] De Gruijl FR, van Kranen HJ, mullenders LV. UV-induced DNA damage, repair, mutations, and oncogenic pathways in skin cancer. J Photochem Photobiol B 2001; 63: 19-27.

[20] Cadet J, Sage E, Douki T. Ultraviolet radiation-mediated damage to cellular DNA. Mutat Res 2005; 571: 3-17.

[21] De Gruijl FR. Photocarcinogenesis: UVA vs UVB. Methods Enzymol 2000; 319: 359-66.

[22] Ravanat JL, Douki T, Cadet J. Direct and indirect effects of UV radiation on DNA and its components. J Photochem Photobiol B 2001; 63: 88-102.

[23] Fritsche E, Schafer C, Calles C, et al. Lightening up the UV response by identification of the arylhydrocarbon receptor as a cytoplasmatic target for ultraviolet B radiation. Proc Natl Acad Sci USA 2007; 104: 8851-6.

[24] Tyrrell RM. Ultraviolet radiation and free radical damage to skin. Biochem Soc Symp 1995; 61: 47-53.

[25] Kielbassa C, Roza L, Epe B. Wavelength dependence of oxidative DNA damage induced by UV and visible light. Carcinogenesis 1997; 18: 811-6.

[26] Berneburg M, Grether-Beck S, Kurten V, et al. Singlet oxygen mediates the UVA-induced generation of the photoaging-associated mitochondrial common deletion. J Biol Chem 1999; 274: 15345-9.

[27] Reimann V, Kramer U, Sugiri D, et al. Sunbed use induces the photoaging-associated mitochondrial common deletion. J Invest Dermatol 2008; 128: 1294-7.

[28] Krutmann J. Ultraviolet A radiation-induced biological effects in human skin: relevance for photoaging and photodermatosis. J Dermatol Sci 2000; Suppl: S22-S6.

[29] Epstein JH. Phototoxicity and photoallergy. Semin Cutan Med Surg 1999; 18: 274-84.

[30] Epstein JH. Phototoxicity and photoallergy in man. J Am Acad Dermatol 1983; 8: 141-7.

[31] De Fabo EC, Noonan FP, Fears T, Merlino G. Ultraviolet B but not ultraviolet A radiation initiates melanoma. Cancer Res 2004; 64: 6372-6.

[32] Wood SR, Berwick M, Ley RD, Walter RB, Setlow RB, Timmins GS. UV causation of melanoma in Xiphophorus is dominated by melanin photosensitized oxidant production. Proc Natl Acad Sci USA 2006; 103: 4111-5. 
[33] Runger TM. Role of UVA in the pathogenesis of melanoma and non-melanoma skin cancer: a short review. Photodermatol Photoimmunol Photomed 1999; 15: 212-6.

[34] Wang SQ, Setlow R, Berwick M, et al. Ultraviolet A and melanoma: a review. J Am Acad Dermatol 2001; 44: 837-46.

[35] Parrish JA. Immunosuppression, skin cancer, and ultraviolet A radiation. N Engl J Med 2005; 353: 2712-13.

[36] Leiter U, Garbe C. Epidemiology of melanoma and nonmelanoma skin cancer--the role of sunlight. Adv Exp Med Biol 2008; 624: 89103.

[37] Pathak MA. Ultraviolet radiation and the development of nonmelanoma and melanoma skin cancer: clinical and experimental evidence. Skin Pharmacol 1991; Suppl 1: 85-94.

[38] Moan J, Dahlback A, Setlow RB. Epidemiological support for an hypothesis for melanoma induction indicating a role for UV A radiation. Photochem Photobiol 1999; 70: 243-7.

[39] Penn I. Cancer in immunosuppressed patients. Transplant Proc 1984; 16: 492-4

[40] London NJ, Farmery SM, Will EJ, Davison AM, Lodge JP. Risk of neoplasia in renal transplant patients. Lancet 1995; 346: 403-6.

[41] O'Donovan P, Perrett CM, Zhang X, et al. Azathioprine and UVA light generate mutagenic oxidative DNA damage. Science 2005; 309: 1871-4.

[42] Tyrrell RM. Solar ultraviolet A radiation: an oxidizing skin carcinogen that activates heme oxygenase-1. Antioxid Redox Signal 2004; 6: 835-40.

[43] Norris PG, Hawk JL. Polymorphic light eruption. Photodermatol Photoimmunol Photomed 1990; 7: 186-91.

[44] Tutrone WD, Spann CT, Scheinfeld N, Deleo VA. Polymorphic light eruption. Dermatol Ther 2003; 16: 28-39.

[45] Schroeder P, Haendeler J, Krutmann J. The role of near infrared radiation in photoaging of the skin. Exp Gerontol 2008; 43: 629-32.

[46] Klotz LO, Holbrook NJ, Sies H. UVA and singlet oxygen as inducers of cutaneous signaling events. Curr Probl Dermatol 2001; 29: 95-113.

[47] Baier J, Maisch T, Maier M, Landthaler M, Baumler W. Direct detection of singlet oxygen generated by UV A irradiation in human cells and skin. J Invest Dermatol 2007; 127: 1498-506.

[48] Starkov AA. The role of mitochondria in reactive oxygen species metabolism and signaling. Ann N Y Acad Sci 2008; 1147: 37-52.

[49] Bedard K, Krause KH. The NOX family of ROS-generating NADPH oxidases: physiology and pathophysiology. Physiol Rev 2007; 87: 245-313.

[50] Beak SM, Lee YS, Kim JA. NADPH oxidase and cyclooxygenase mediate the ultraviolet $\mathrm{B}$-induced generation of reactive oxygen species and activation of nuclear factor-kappaB in $\mathrm{HaCaT}$ human keratinocytes. Biochimie 2004; 86: 425-9.

[51] Wang H, Kochevar IE. Involvement of UVB-induced reactive oxygen species in TGF-beta biosynthesis and activation in keratinocytes. Free Radic Biol Med 2005; 38: 890-7.

[52] Pike LJ. Rafts defined: a report on the keystone symposium on lipid rafts and cell function. J Lipid Res 2006; 47: 1597-8.

[53] Yamada E. The fine structure of the gall bladder epithelium of the mouse. J Biophys Biochem Cytol 1955; 1: 445-58.

[54] Palade G. Fine structure of blood capillaries. J Appl Phys 1953; 24: 1424.

[55] Brown DA, London E. Structure and origin of ordered lipid domains in biological membranes. J Membr Biol 1998; 164: 10314.

[56] Pierini LM, Maxfield FR. Flotillas of lipid rafts fore and aft. Proc Natl Acad Sci USA 2001; 98: 9471-3.

[57] Gniadecki R, Bang B. Flotillas of lipid rafts in transit amplifying cell-like keratinocytes. J Invest Dermatol 2003; 121: 522-8.

[58] Gniadecki R, Christoffersen N, Wulf HC. Cholesterol-rich plasma membrane domains (lipid rafts) in keratinocytes: importance in the baseline and UVA-induced generation of reactive oxygen species. J Invest Dermatol 2002; 118: 582-8.

[59] Valencia A, Rajadurai A, Carle AB, Kochevar IE. 7Dehydrocholesterol enhances ultraviolet A-induced oxidative stress in keratinocytes: roles of NADPH oxidase, mitochondria, and lipid rafts. Free Radic Biol Med 2006; 41: 1704-18.

[60] Valencia A, Kochevar IE. Nox1-based NADPH oxidase is the major source of UVA-induced reactive oxygen species in human keratinocytes. J Invest Dermatol 2008; 128: 214-22.
[61] Charman CR, Ryan A, Tyrrell RM, et al. Photosensitivity associated with the Smith-Lemli-Opitz syndrome. Br J Dermatol 1998; 138: 885-8.

[62] Anstey AV, Ryan A, Rhodes LE, et al. Characterization of photosensitivity in the Smith-Lemli-Opitz syndrome: a new congenital photosensitivity syndrome. Br J Dermatol 1999; 141: 406-14.

[63] Anstey AV, Taylor CR. Photosensitivity in the Smith-Lemli-Opitz syndrome: the US experience of a new congenital photosensitivity syndrome. J Am Acad Dermatol 1999; 41: 121-3.

[64] Fitzky BU, Witsch-Baumgartner M, Erdel M, et al. Mutations in the Delta7-sterol reductase gene in patients with the Smith-LemliOpitz syndrome. Proc Natl Acad Sci USA 1998; 95: 8181-6.

[65] Valencia A, Kochevar IE. Ultraviolet A induces apoptosis via reactive oxygen species in a model for Smith-Lemli-Opitz syndrome. Free Radic Biol Med 2006; 40: 641-50.

[66] Mahns A, Wolber R, Stab F, Klotz LO, Sies H. Contribution of UVB and UVA to UV-dependent stimulation of cyclooxygenase-2 expression in artificial epidermis. Photochem Photobiol Sci 2004; 3: 257-62.

[67] Megha, Bakht O, London E. Cholesterol precursors stabilize ordinary and ceramide-rich ordered lipid domains (lipid rafts) to different degrees: implications for the Bloch hypothesis and sterol biosynthesis disorders. J Biol Chem 2006; 281: 21903-13.

[68] Grether-Beck S, Salahshour-Fard M, Timmer A, et al. Ceramide and raft signaling are linked with each other in UVA radiationinduced gene expression. Oncogene 2008; 27: 4768-78.

[69] Caughman SW, Li LJ, Degitz K. Human intercellular adhesion molecule-1 gene and its expression in the skin. J Invest Dermatol 1992; 98: 61S-5S.

[70] Krutmann J, Grewe M. Involvement of cytokines, DNA damage, and reactive oxygen intermediates in ultraviolet radiation-induced modulation of intercellular adhesion molecule-1 expression. J Invest Dermatol 1995; 105: 67S-70S.

[71] Grether-Beck S, Olaizola-Horn S, Schmitt H, et al. Activation of transcription factor AP-2 mediates UVA radiation- and singlet oxygen-induced expression of the human intercellular adhesion molecule 1 gene. Proc Natl Acad Sci U S A 1996; 93: 14586-91.

[72] Grether-Beck S, Bonizzi G, Schmitt-Brenden H, et al. Nonenzymatic triggering of the ceramide signaling cascade by solar UVA radiation. EMBO J 2000; 19: 5793-800.

[73] Megha, London E. Ceramide selectively displaces cholesterol from ordered lipid domains (rafts): implications for lipid raft structure and function. J Biol Chem 2004; 279: 9997-10004.

[74] Cohen AW, Hnasko R, Schubert W, Lisanti MP. Role of caveolae and caveolins in health and disease. Physiol Rev 2004; 84: 134179.

[75] Mercier I, Jasmin JF, Pavlides S, et al. Clinical and translational implications of the caveolin gene family: lessons from mouse models and human genetic disorders. Lab Invest 2009; 89: 614-23.

[76] Sando GN, Zhu H, Weis JM, Richman JT, Wertz PW, Madison $\mathrm{KC}$. Caveolin expression and localization in human keratinocytes suggest a role in lamellar granule biogenesis. J Invest Dermatol 2003; 120: 531-41.

[77] Bist A, Fielding PE, Fielding CJ. Two sterol regulatory elementlike sequences mediate up-regulation of caveolin gene transcription in response to low density lipoprotein free cholesterol. Proc Natl Acad Sci USA 1997; 94: 10693-8.

[78] Frank PG, Marcel YL, Connelly MA, et al. Stabilization of caveolin-1 by cellular cholesterol and scavenger receptor class B type I. Biochemistry 2002; 41: 11931-40.

[79] Graf GA, Connell PM, van der Westhuyzen DR, Smart EJ. The class B, type I scavenger receptor promotes the selective uptake of high density lipoprotein cholesterol ethers into caveolae. J Biol Chem 1999, 274: 12043-8.

[80] Schlegel A, Pestell RG, Lisanti MP. Caveolins in cholesterol trafficking and signal transduction: implications for human disease. Front Biosci 2000; 5: D929-37.

[81] Simons K, Toomre D. Lipid rafts and signal transduction. Nat Rev Mol Cell Biol 2000; 1: 31-9.

[82] Schlegel A, Schwab RB, Scherer PE, Lisanti MP. A role for the caveolin scaffolding domain in mediating the membrane attachment of caveolin-1: the caveolin scaffolding domain is both necessary and sufficient for membrane binding in vitro. $\mathrm{J}$ Biol Chem 1999; 274: 22660-7. 
[83] Couet J, Sargiacomo M, Lisanti MP. Interaction of a receptor tyrosine kinase, EGF-R, with caveolins. Caveolin binding negatively regulates tyrosine and serine/threonine kinase activities. J Biol Chem 1997; 272: 30429-38.

[84] Cohen AW, Combs TP, Scherer PE, Lisanti MP. Role of caveolin and caveolae in insulin signaling and diabetes. Am J Physiol Endocrinol Metab 2003; 285: E1151-60.

[85] Volonte D, Galbiati F, Pestell RG, Lisanti MP. Cellular stress induces the tyrosine phosphorylation of caveolin-1 (Tyr(14)) via activation of p38 mitogen-activated protein kinase and c-Src kinase: evidence for caveolae, the actin cytoskeleton, and focal adhesions as mechanical sensors of osmotic stress. J Biol Chem 2001; 276: 8094-103.

[86] Grether-Beck S, Salahshour-Fard M, Brammertz D, Brenden H, Felsner IK, J. The role of the raft-associated proteins src-kinase and caveolin-1 in ultraviolet A radiation -induced signaling in human keratinocytes. J Invest Dermatol 2005; 124: A135.

Received: June 18, 2009

Revised: June 27, 2009

Accepted: June 27, 2009

(C) Grether-Beck and Krutmann; Licensee Bentham Open.

This is an open access article licensed under the terms of the Creative Commons Attribution Non-Commercial License (http://creativecommons.org/licenses/by-nc/

3.0/) which permits unrestricted, non-commercial use, distribution and reproduction in any medium, provided the work is properly cited. 